\title{
ACKNOWLEDGMENTS
}

\section{$7 \mathrm{e}$ wish to thank the following people for helping us to understand and then translate some of the difficulties.}

Dominique Borde

Claire Brisset

Karen Fenn

Russell Grigg

Mireille Perche

Susan Suleiman

Bob Vallier

and Julia Kristeva 
